\title{
Exploring the Concepts of Fidelity and Adaptation in the Implementation of Project Based Learning in the Elementary Classroom: Case Studies from Qatar
}

\author{
Xiangyun Du \\ Qatar University \\ Doha, Qatar \\ Youmen Chaaban \\ Azm University \\ Tripoli, Lebanon \\ Yasameen AL Mabrd \\ Qatar University \\ Doha, Qatar
}

\begin{abstract}
This study explored teachers' first-year experiences with Project Based Learning in the context of a system-wide initiative involving its implementation in Qatari elementary government schools. Participants were 11 English as a Foreign Language EFL teachers distributed among three schools, constituting the cases in the current study. Findings from interviews, observations and document reviews revealed the complexity inherent in balancing fidelity and adaptation. Results suggest that teachers tend to resort to adaptation in the presence of various impeding factors at the personal and organizational levels. To alleviate these contextual challenges and improve fidelity towards PBL implementation, several recommendations are discussed.
\end{abstract}

Keywords: project-based learning; fidelity of implementation; adaptation; EFL; elementary education; Qatar.

\section{Introduction}

Project Based Learning (PBL) is considered an innovative approach to learning adopted by many educators around the world as facilitating the acquisition of $21^{\text {st }}$ century skills (Bell, 2010). A substantial number of studies have reported various benefits of PBL, specifically in higher education, resulting in graduates equipped with higher-order thinking skills, competencies, and values demanded by the work place (Du, Ebead, Sabah, Ma \& Naji, 2019; Helle, Tynjälä \& Olkinuora, 2006; Lee, Blackwell, Drake \& Moran, 2014; Prince \& Felder, 2006). 
In recent years, many $\mathrm{K}-12$ schools have reported the increasingly positive influence of PBL on student learning, motivation, engagement, creative abilities, and thinking skills (Grant, 2011; Tamin \& Grant, 2013; Wurdinger, 2016). While the majority of studies have focused on secondary schooling, other studies have reported the potential of bringing PBL into primary schools for similar reasons (Kaldi, Filippatou, \& Govaris, 2011; Nariman \& Chrispeels, 2016). Most notably, these studies have revealed benefits on the development of reasoning and thinking skills, specifically in science and mathematics (Dole, Bloom \& Doss, 2017; Drake \& Long, 2009; Jerzembek, G., \& Murphy, 2013; Merritt, Lee, Rillero, \& Kinach, 2017). Nevertheless, PBL remains seldom implemented at a systemic level in primary education (Wurdinger, 2016).

While the majority of studies have focused on the influence of PBL on student learning outcomes (Du, Ebead, Sabah, Ma \& Naji, 2019), few studies have examined teachers' implementation of PBL (Hmelo-Silver, 2012; Tamin \& Grant, 2013). Despite the variance that may exist among teachers' implementation of any innovative approach, fidelity of implementation is rarely reported in educational studies that examine interventions in K-12 settings ( $\mathrm{O}^{\prime}$ Donnell, 2008). Several factors influence fidelity of implementation, including whether teachers believe the innovation is appropriate to their educational goals and beneficial to their student learning (Fullan, 2014). Rather than adopting an innovation, teachers have often been found to adapt it to fit their specific contexts (Ravitz, 2010). However, little is known about the way teachers balance adaptation and fidelity of implementation, as well as contextual factors that can be attributed to such variations in practices (Hmelo-Silver, 2012).

Clearly, the implementation of PBL in the socio-cultural context of K-12 schools is a complex phenomenon that requires further investigation to evaluate the factors that may enhance or impede its success (Jerzembek \& Murphy, 2013). Therefore, further qualitative studies are needed to investigate how teachers implement PBL (Hmelo-Silver, 2012; Tamin \& Grant, 2013), how they negotiate meaning during the process of PBL implementation (Al Said, Du, ALKhatib, Romanowski \& Barham, 2019; Mitchell, Foulger \& Wetzel, 2008), and how they balance adaptation and fidelity of PBL implementation (Hmelo-Silver, 2012).

The current study aimed to explore English as a Foreign Language (EFL) teachers' first year experiences with PBL in the context of a system-wide reform initiative involving its introduction into primary education in Qatari government schools. It also aimed to fill the literature gap regarding the implementation of PBL in the primary school context, with a particular focus on the balance between adaptation and fidelity of implementation by analyzing EFL teachers' practices and the contextual factors influencing their instructional decision-making. 


\section{Literature review}

\subsection{Project Based Learning}

The term PBL can refer to either problem-based learning, project-based learning, or a combination of both. In the context of the current study, and following the official documents of the Ministry of Education and Higher Education in Qatar (MOEHE), PBL refers specifically to Project Based Learning. Among the many definitions available in the literature, the current study defines PBL as "an instructional (and curricular) learner-centered approach that empowers learners to conduct research, integrate theory and practice, and apply knowledge and skills to develop a viable solution to a defined problem" (Savery, 2006, p.9).

Thomas (2000) set five criteria for PBL, such that projects should be central to the curriculum, student-driven and realistic, focused on problems that drive the students to struggle with major concepts, and structured in ways that involve students in constructivist investigations. Furthermore, Grant (2011) described the common features of PBL as including an anchor of the activity, a task, an investigation, provision of resources, scaffolding, collaboration, and opportunities for reflection and transfer. Emphasizing a systemwide change to PBL, six principles can be summarized (Dole, Bloom \& Doss, 2017; Hmelo-Silver, 2012; Thomas, 2000), including: (1) curriculum should be centered around and driven by the project, (2) assessment should be constructively aligned with the objectives and activities of the project, (3) activities should include real world challenges and authentic topics, and involve the use of technology, (4) students should engage in problem solving that involves multi-disciplinary knowledge, (5) students should participate in decision-making processes for identifying learning needs, choice of topic, and materials, and (6) students should work collaboratively in teams, assuming responsibility for their learning.

In the context of the EFL classroom, PBL has been shown to improve students' language proficiency, and enhance their higher-order thinking and problemsolving skills (Beckett, 2006; Stoller, 2006). Nevertheless, existing studies have focused on adult learners, while the feasibility and potential of using PBL in the EFL primary classroom remains uncertain, specifically when students' proficiency levels are only beginning to emerge (Fragoulis \& Tsiplakides, 2009). Considering the demands for high levels of engagement in diverse learnercentered activities, PBL may be considered more appropriate for learners who possess a certain degree of language proficiency, rather than those who are still struggling with basic language acquisition (Ruan, Duan \& Du, 2015).

\subsection{Fidelity of implementation}

Although there have been various large-scale initiatives encouraging learnercentered instruction, several studies reveal inconsistent results concerning teachers' actual adoption of innovative instructional practices ( $\mathrm{O}^{\prime}$ Donnell, 2008; Ravitz, 2010). For a reform initiative to be effective, it is essential that teaches receive clear guidelines for the kinds of instructional practices recommended, as well organizational preparation and support systems, so they can become capable of managing the implementation with fidelity (Correnti \& Rowan, 2007). 
Implementation, referring to "what a program consists of when it is delivered in a particular setting" (Durlak \& DuPre, 2008, p. 329), has been shown to impact the outcome and success of an innovation (Dane \& Schneider, 1998). In K-12 core curriculum interventions, implementation refers to using an innovation "faithfully in practice - that is, to use it as it is supposed to be used, as intended by the developer" (Fullan, 2007, p. 40). In their framework of fidelity of implementation, Dane and Schneider (1998) identified five aspects that are essential in implementing any innovation, including (1) adherence, whether the components of the program are being delivered as designed; (2) dosage, the number, frequency, and time devoted for implementation; (3) quality, the manner in which program components are delivered; (4) responsiveness, the extent to which the program stimulates the interest of participants; and (5) program differentiation, the extent to which the program is unique and different from other interventions. Additionally, Durlak and DuPre (2008) suggested paying attention to three further aspects in the study of implementation, including: (1) monitoring of control, i.e., the nature and amount of services received by participants; (2) program scope, i.e., rate of involvement and representativeness of the participants; and (3) adaptation, i.e., changes and modifications made during implementation. Being employed in disciplines such as business, health science, and psychology for decades, the fidelity of implementation framework has been regarded as useful in understanding and interpreting implementation practices in educational settings (Troyer, 2017).

In their systematic literature review, Durlak and DuPre (2008) emphasized that fidelity of implementation is crucial to the outcomes of the innovation; however, they found that no implementation has $100 \%$ fidelity. Consequently, adaptation is an inevitable and sometimes necessary process that may increase the likelihood that the innovation meets the local needs of participants. Therefore, the balance between fidelity and adaptation aimed at maximizing the outcome of implementation is an area that demands further research (Dane \& Schneider, 1998; Troyer, 2017).

\subsection{Contextual factors influencing fidelity of implementation}

Previous studies have identified a variety of contextual factors that influence implementation (Durlak \& DuPre, 2008). Such factors may be divided into: (1) providers and innovations, (2) aspect of the delivery system (institutional facilities and supports), and (3) the support system (training and technical assistance).

In PBL literature, several challenges have been identified to hinder teachers' fidelity of implementation. Ertmer \& Simons (2006) summarized three major challenges for teachers to (1) create a culture of collaboration and interdependence, 2) adjust to changing roles, and 3) scaffold student learning and performance. Tamin and Grant (2013) suggested five aspects confronting teachers when using PBL in their classrooms: (1) developing constructivist beliefs, (2) adopting new instructional strategies, (3) selecting topics and balancing PBL with overall curricular demands, (4) managing classroom dynamics, and (5) creating collaborative classroom environments. In addition to 
these individual factors, Lam, Cheng \& Choy (2010) emphasized interpersonal factors, such as the lack of cooperation among teachers, as further important, yet challenging factors. From an organizational perspective, several factors further impede teachers' implementation practices, including policies at local, regional and national levels, supports with training and professional development opportunities, and sufficient time for change and growth (Ravitz, 2010).

Although teachers' individual and collective readiness (Fullan, 2014) and school supports (Lam, Cheng \& Choy, 2010) have been emphasized for PBL implementation, little evidence is available that investigates all such factors from teachers' perspective (Hmelo-Silver, 2012; Ravitz, 2010). Implementing PBL requires a significant commitment and focus for teachers to overcome the challenges that are context-bound (Ravitz, 2010), therefore it is necessarily to explore the contextual factors that influence their choices and practices during implementation.

In the Qatari context, recent educational policies have mandated several reform initiatives with the goal of providing quality education to all students (Al Said, Du, ALKhatib, Romanowski \& Barham, 2019). During the 2017/2018 academic year, a statewide initiative was announced by the MOEHE introducing PBL into several subject areas at the primary level, including EFL. Considering it was the first time that PBL was implemented in Qatar at a systemic level, it was necessary to examine how the implementation was carried out before exploring the quality of outcomes (Ravitz, 2010). Therefore, this study aimed to explore how EFL teachers understood PBL, how they experienced their initial implementation practices, and what contextual factors supported or challenged their fidelity of implementation. The following questions guided the current study:

1. How do EFL teachers describe their first-year experience of implementing PBL in Qatari primary government schools?

2. Which contextual factors influence teachers' adaptation and fidelity during their first-year experience of implementing PBL?

\section{Methodology}

\subsection{Qualitative case study design and participants}

The majority of earlier empirical studies on the fidelity of implementation in educational settings offered quantitative findings ( $\mathrm{O}^{\prime}$ Donnell, 2008). Despite their importance, such quantitative results may not adequately illustrate the complexity inherent in educational change processes $(\mathrm{Hu}, 2002)$. By employing a qualitative research design, the current study, therefore, aimed to unravel the contextual and dynamic nature of teacher's experiences with PBL implementation (Creswell \& Poth, 2018).

A case study research design was employed involving three schools as different research sites, thus representing the complex interactions and dynamics among multiple factors (Stake, 1995). According to Stake (1995), the holistic nature of 
the case study allows researchers to dig into the interrelationships between the phenomenon and its context through qualitative empirical data. The choice of case study design is also based on the premise that teachers' perceptions and practices of implementation are not only subject to prior personal experiences and backgrounds, but also sociocultural and institutional factors in their situated contexts $(\mathrm{Hu}, 2002)$.

Upon receiving approval from Ministry of Education and Higher Education (MOEHE) in Qatar and the university research ethics office, a request to participate in the current study was sent to over 20 primary government schools from different districts. Among the schools that agreed to participate, three were randomly chosen for inclusion in the current study. The criteria of inclusion consisted of all primary government schools whose workforce were female teachers, in adherence to government regulations.

A convenient sampling technique was employed. Each of the school cases consisted of 4-6 EFL teachers, with a total of 14. Among these teachers, 11 volunteered to participate in this study. All participants were female nativeArabic speakers but could speak English fluently. Only teacher 4 and 11 attended a 2-day PBL training workshop offered by the MOEHE. Participant details are presented in Table 1.

Table 1: Participants' background information

\begin{tabular}{ccccccc}
\hline $\begin{array}{c}\text { School } \\
\text { code }\end{array}$ & $\begin{array}{c}\text { Teacher } \\
\text { code }\end{array}$ & $\begin{array}{c}\text { Years of } \\
\text { teaching } \\
\text { experience }\end{array}$ & $\begin{array}{c}\text { Grade } \\
\text { currently } \\
\text { teaching }\end{array}$ & $\begin{array}{c}\text { Availability of } \\
\text { Lesson Plans } \\
(1 \text { and } 2)\end{array}$ & $\begin{array}{c}\text { Observati } \\
\text { on } \\
(1 \text { and 2) }\end{array}$ & $\begin{array}{c}\text { Previous } \\
\text { PBL } \\
\text { experience }\end{array}$ \\
\hline A & 1 & 5 & 4 & $x$ & & Yes \\
& 2 & 4 & 3 and 5 & $x$ & $\mathrm{x}$ & No \\
& 3 & 5 & 6 & & $\mathrm{x}$ & No \\
B & 4 & 3 & 5 & $\mathrm{x}$ & $\mathrm{x}$ & Yes \\
& 5 & 5 & 4 & $\mathrm{x}$ & $\mathrm{x}$ & No \\
& 6 & 4 & 3 & $\mathrm{x}$ & $\mathrm{x}$ & No \\
C & 7 & 2 & 3 & $\mathrm{x}$ & $\mathrm{x}$ & Yes \\
& 8 & 2 & 4 & $\mathrm{x}$ & $\mathrm{x}$ & Yes \\
& 9 & 3 & 6 & $\mathrm{x}$ & $\mathrm{x}$ & Yes \\
\hline
\end{tabular}

\subsection{Data collection}

Multiple sources of data were generated from semi-structured interviews, classroom observations and document reviews, which are recommended data collection tools in qualitative case study research (Stake, 1995; Merriam, 1998).

Document reviews included MOEHE guidelines, implementation and evaluation forms, and lesson plans developed by participating teachers for their PBL sessions. Data from document reviews provided background information regarding the definition of PBL, intended objectives and learning outcomes, as well as mandated procedures and evaluation methods. 
Due to the restricted nature of implementation, classroom observations became difficult and only 8 sessions were documented during the first project rounds, and 3 sessions were observed during the second project rounds ${ }^{1}$. Hence, observation data played a supportive role to partially understand the practice of PBL and to triangulate qualitative data from the semi-structured interviews. As case study sites are bound to differ in response to educational research, school site $\mathrm{C}$ further facilitated the observation of three teacher preparation meetings, thus providing access to data on the manner in which teachers collaborated, negotiated and reached consensus on mandated policy requirements.

Participants were interviewed twice during this study; the first interview was conducted at the beginning of the academic year 2017/2018, and the second interview was conducted towards the end of that same year. The purpose of collecting two rounds of interview data was to provide participants the opportunity to review and reflect upon the process of project implementation, thus gaining a deeper understanding of their beliefs, experiences, opinions, and challenges (Kvale \& Brinkmann, 2009). Initial interview questions were developed following the framework of PBL principles as summarized in this study. A preliminary review of official documents and observation data raised further questions for the second interview. All interviews took place in the participants' schools, each lasting 30-60 minutes. The interviews were conducted in either English or Arabic as chosen by the participant. They were audiorecorded, transcribed and translated into English for content analysis.

\subsection{Data analysis}

Multiple strategies were used for data analysis. Data validation strategies employed included cross-case synthesis and comparison (Yin, 2014), triangulation of data sources (Yin, 2014; Stake, 1995, Merriam, 1998) and researcher validation (Stake, 1995).

The overall analysis process in this study involved an integrated approach including firstly several rounds of comparing and contrasting all sources of data, then combining a theory-driven analysis and a thematic analysis (Kvale \& Brinkmann, 2009). Afterwards, results from the first interview, in addition to initial analyses of documents and observations, were used to develop the second round of interview guidelines, in order to facilitate member checking of first semester experiences, comparisons with second semester experiences, and reflection on the entire experience. The fidelity of implementation framework (Dane \& Schneider, 1998) and the PBL principles constituted the lens used during the coding, categorization, and summary of sub-themes running through the whole set of data (Saldaña, 2016).

\section{Findings}

This section reports findings following the framework of fidelity of implementation (Dane \& Schneider, 1998) and structured by conditions of PBL

\footnotetext{
${ }^{1}$ These observations were cut short due to project cancellation as decided by the MOEHE at the end of the academic year to accommodate for religious celebrations.
} 
implementation (adherence, dosage, program differentiation) and implementation processes (delivery and participants responsiveness).

\subsection{Conditions of PBL implementation}

Initially, the MOEHE policy document allocated twelve class sessions (50 minutes per session) to be assigned for the implementation of PBL across the two semesters. Two weeks into the academic year, a decision was made to reduce this number to a mere four sessions. The modified version of the policy document allowed schools the freedom to decide on the sessions dedicated for PBL. Resources for project work such as materials and posters would be provided by MOEHE and the schools.

Accordingly, EFL teachers were required to complete two projects each lasting two months. Teachers were directed to allocate two class sessions for each project. During the first session, teachers had to initiate the project, explain expected outcomes, topic requirements and procedures, and assign groups. The second session was allocated for group presentations, assessment and reflections. All other class sessions during the semesters were to be taught in the regular method. Accordingly, students were to complete their projects mostly outside school time. Students were assessed in the usual assessment method defined by MOEHE with no additional assessment focusing on PBL outcomes. At the end of each project, teachers were to complete documentation requirements, including lesson plans and reflection forms, for inspection by MOEHE specialists.

In the form of a two-day workshop conducted early in the academic year, most EFL coordinators participated in professional development provided by the MOEHE. Following their participation in the workshop, subject coordinators were required to organize school-based training activities to support all teachers within their departments to develop PBL lesson plans in a collaborative manner.

According to interview data, participants noted other initiatives mandated by the MOEHE, which were being experimented in government schools alongside the PBL initiative. All three case study schools were involved in various initiatives including experiential learning (School A and B), a giftedness program (School C), and extracurricular activities within school hours (School A, $B$, and $C$ ). These initiatives had rolled out approximately the same time during the implementation of the PBL program. Previous initiatives were further continued, such as theatrical performances and book clubs.

\subsection{PBL implementation processes}

Reports on implementation processes include teachers' understanding of PBL, their instructional practices in accordance to PBL principles, and their perceptions of PBL appropriateness and benefits.

\subsubsection{Teachers' understanding of PBL}

To explore teachers' understanding of PBL, they were asked to define what they believed were the major characteristics this approach during the first interview and provide new insights in regard to their understanding of PBL during the second interview. 
During the first interviews, participants grappled in their attempt to articulate their understanding of a new concept. They provided a variety of definitions and characteristics based on first impressions and limited experiences. Based on thematic analyses of interview data, four categories emerged, as shown in Table 2.

Table 2: Characteristics of PBL as perceived by the teachers

\begin{tabular}{|c|c|c|}
\hline Categories & $\begin{array}{l}\text { Teacher } \\
\text { code }\end{array}$ & Characteristics of PBL \\
\hline \multirow{3}{*}{1} & $\mathrm{~T} 1$ & $\begin{array}{c}\text { "...group work for students working on specific topic and they } \\
\text { have to search and create outcomes." }\end{array}$ \\
\hline & T9 & $\begin{array}{l}\text { "by MOEHE request, the teacher chooses a topic from the } \\
\text { textbook and implements it as group work..." }\end{array}$ \\
\hline & T10 & $\begin{array}{c}\text { "PBL is teamwork...the outcomes should be achieved with } \\
\text { teachers having the responsibility of following up with their } \\
\text { students" }\end{array}$ \\
\hline \multirow{3}{*}{2} & $\mathrm{~T} 2$ & $\begin{array}{l}\text { "we didn't receive enough training regarding this topic to } \\
\text { define it well and give you my point of view, but what I } \\
\text { understood from the guideline is it is self-learning for students }\end{array}$ \\
\hline & T7 & $\begin{array}{l}\text { to search for information" } \\
\text { "Self-learning, letting students think out of the box" }\end{array}$ \\
\hline & $\mathrm{T} 8$ & $\begin{array}{c}\text { "PBL is to let students think, to imagine things, to be creative in } \\
\text { making projects and new things" }\end{array}$ \\
\hline \multirow{5}{*}{3} & T3 & $\begin{array}{l}\text { "students learn through making research by themselves } \\
\text { without the interfering of the teachers" }\end{array}$ \\
\hline & T5 & $\begin{array}{c}\text { "PBL is research that students do based on their academic } \\
\text { level" }\end{array}$ \\
\hline & T6 & $\begin{array}{c}\text { "PBL is a project in which the teacher displays a sample to their } \\
\text { students to design their own research: posters, writing, } \\
\text { PPT, ...practiced in groups" }\end{array}$ \\
\hline & $\mathrm{T} 4$ & $\begin{array}{c}\text { "...select what is suitable for your students and how to } \\
\text { introduce the driven question, and how to let students search } \\
\text { information." }\end{array}$ \\
\hline & T11 & $\begin{array}{l}\text { "selecting a topic from the book unit...let student do research, } \\
\text { making modifications according to the students' level" }\end{array}$ \\
\hline
\end{tabular}

First, three teachers $(\mathrm{T} 1,9,10)$ defined PBL focusing on teamwork, where students help each other in producing a product under the teacher's guidance. Second, three teachers $(\mathrm{T} 2,7,8)$ defined PBL as a tool to enhance self-directed learning, including searching for information and producing a pre-planned product. Third, five teachers $(\mathrm{T} 3,5,6,4,11)$ believed that the core of PBL was conducting research. In the process, students acquired knowledge and skills through searching for information, writing, and making presentations in the forms of posters or PowerPoints. As teachers, their role involved guiding students throughout the process and ensuring that they were on track. In particular, two teachers (T4 and 11) stated that PBL should begin with a driving question that leads students to search for information, as the teacher observes and guides their learning. 
Four teachers believed they had previously experienced PBL as a teacher, nevertheless two of them documented their confusion in distinguishing past project work and current PBL. As one participant stated:

"In the textbooks, there are already exercises named project work, and we used to do that, in my opinion there is no difference. It is only extra load on the teacher to call it differently" (T1, In1)

\subsubsection{Teachers' instructional practices in accordance to PBL principles}

All three schools implemented PBL following MOEHE guidelines, which included a document illustrating clear and specific procedures. All sources of data revealed participants' close adherence to such guideline. Accordingly, teachers chose a theme (or topic) from their existing curriculum, i.e., the textbook, and worked out a lesson plan for the design of the project. They presented the projects during the first session allocated for PBL, informing students of the topics, timelines, and expected outcomes. Students were divided into groups with a leader appointed in each group who became responsible for organizing the group project and communicating with the teacher. In project end session, students presented their products and conducted peer assessment and self-reflection.

All teachers believed that this was a good strategy for primary education because their curriculum was sufficiently broad, thus enabling them to identify themes for student projects. Examples of themes include tourism in Qatar, recycling used materials, road safety, healthy food, and sports and healthy living styles. Expected outcomes were posters, PowerPoint presentations, game boards, and models, among other types of visual presentations.

Nevertheless, data from lesson plans, classroom observation and interviews revealed teachers' adaptation of PBL implementation. Firstly, adaptation was mentioned by three teachers (T6, 10 and 11) due to a lack of understanding, limited resources and local needs. As one teacher mentioned,

"Although we follow the procedures, the same time we have to adapt because as teachers we sometimes don't really understand what they meant. In particular, when we don't have sufficient materials to provide to students." (T6, In1)

Secondly, the majority of participants noted the necessity of adapting their implementation of PBL according to their students' age groups. While participants believed students in grades five and six were capable of conducting research independently, they confirmed that students in grades three and four had major difficulty in understanding what they were supposed to do. They claimed that their students lacked the most basic level of language proficiency, and hence were not capable of conducting research on their own. Most notably, participants agreed that these students were not ready for finding solutions to real-life issues nor thinking critically about problematic topics. In their attempt to adapt the implementation of PBL to fit the needs of their students, various strategies were reported from the classroom observations and interview data, 
specifically in providing more direct instruction for lower elementary students and reducing expectation levels for project outcomes. As one participant mentioned:

"I taught grade three last semester, the students wait for me to explain all details and it is hard for them to understand what they should do for a project. I also teacher grade 5 and students are better to understand their roles and how to work on a project." (T2, In2)

By contrast, those participants who taught upper elementary students in grades five and six described them as having more autonomy to initiate new ideas, being capable of addressing complex topics related to real life challenges, and possessing the skills needed for problem solving, group formation, and carrying out project demands. Specifically, grade six teachers reported their positive surprise with student outcomes; for example, students had designed an online game for increasing public awareness for recycling and environmental protection and created an Instagram account for branding tourism in Qatar.

\subsubsection{Teachers' perceptions of appropriateness and benefits of PBL}

During the second interview, all participants reflected on the benefits of PBL in the primary classroom. Despite the unsatisfactory conditions experienced during the initial implementation of PBL, the majority of participants reported the appropriateness of PBL as an innovative approach for the teaching and learning of EFL, in condition that the implementation process be improved. As one teacher noted:

"PBL will undoubtedly be beneficial for us in English subject in primary schools if they can be implemented in a more organized way and with more support provided." (T4, In2)

Several benefits noted by the participants included enhancing students' learning opportunities, rather than being restricted to the textbook. Participants believed that students were able to explore several sources of learning on their own, such as searching for information on the Internet and using diverse technological tools for project processes and products. One teacher explained:

"My students improved reading skills because they spent lots of time searching for information and reading for the projects. It made also better their writing when they have to sum up the information and prepare for their presentation. In the process they also improve their listening and speaking." (T3, In2)

Seven teachers mentioned increased motivation as one of the major benefits of PBL. As one teacher stated:

"Last semester we struggle partly due to student low motivation because they did not understand the concept (of PBL) and they did not make efforts as expected. This semester they started to see the positive aspects 
and they are more enthusiastic about new ideas and the project outcomes." (T5, In2)

Further, six teachers mentioned their students connected their interests and hobbies to the project products. For example, several student groups used drawing for posters to present their results. Six teachers observed student growth in creativity and maturity, as one teacher said:

"Some students know what they are interested in and they gave suggestions to teachers on what topics to work on and how to develop new ideas. I am surprised at the independence and maturity they demonstrated." (T10, In2)

Nevertheless, three teachers (T1, 2, 6) expressed their negative opinions on the limited benefits of PBL, mainly due to the lack of organizational support. As one teacher noted:

"I don't think there are much gaining in student skills in the current conditions... things have to improve to make it more beneficial." (T2, In2)

\subsection{Challenges in initial implementation of PBL}

During the first round of interviews, participants expressed feelings of insecurity and doubt, mainly due to a lack of knowledge and skill in implementing PBL, as most participants did not have any prior experience with PBL as learners and had not received sufficient professional development training. As one teacher commented:

"...many teachers found themselves lost; they don't know what to choose, which topic, or how long...there was no training, no support..." (T6, In1)

In comparing the two PBL semesters, some participants reported several changes in the implementation of PBL. While four teachers reported no change and improvement, seven participants documented notable improvements to their confidence and experiences in planning, organizing and facilitating the projects, as one teacher explained:

"Last semester we did not know how to make the plan to make it work for students, this semester we are more experienced and better prepared for planning of project topics, materials, student groups and schedule." (T3, In2)

Second, a major concern expressed was whether PBL was a suitable approach at the elementary level. Although more than half of the participants reported increased confidence and belief in this matter, a few teachers were still in doubt. However, even for those who gained competence, all participants expressed concern for the procedures mandated in the policy guidelines. For instance, participants considered the evaluation forms for PBL implementation too complicated for their students, especially lower elementary students who did 
not possess the language proficiency to complete as required. In the peer assessment forms, all students were expected to grade each other on a wide range of abilities including reflection. As one teacher noted:

"Even we teachers are not confident in grading students on their ability to reflect, not to mention the students at grade three or four." (T11, In1)

Third, all teachers reported time constraints as a major challenge, especially since PBL was considered an add-on to other curricular requirements. Further, participants unanimously agreed that implementing PBL during two formal class sessions was considered insufficient. One teacher explained:

"At least I have to give them hints, not just tell them this is the topic and I want you to do something by your own... they were shocked at the first session. So, they were between understanding the topic you want them to work on and the teamwork, how to divide them into groups and what kind of products they have .... all of this must be done in one session!" (T4, In2)

This issue became even more challenging in the second semester which was cut short by MOEHE. The second PBL session in which students were to submit and present their projects was cancelled. All participants mentioned the stressful experience of having to complete the projects, especially for students who were obliged to complete their projects for EFL and three other subjects. As one teacher said:

"Time is the issue and this semester did not change at all, but more in a rush. Students don't have much time to work together on their projects during school hours. Our school would not allow them to discuss projects in the school because there are many classes to finish ahead of schedule. There are four subjects they have to deliver project outcomes, so they are confused, and they feel lost...which project to complete first...this put pressure on students." (T5, In2)

Fourth, participants faced challenges in teacher collaboration. Although teachers were accustomed to working together on a common lesson plan for each grade, they faced difficulties in planning a PBL lesson, for which they lacked knowledge and understanding. As one teacher explained:

"Usually we divide the tasks to work out common lesson plans for the same grade, it was easy because we just follow the guidelines... the PBL lesson plan is very difficult, we have no experiences and none of us know how to do it. We are all confused but we don't want to say it... and how can we share the same lesson plan with the limited resources?" (T3, In1)

Furthermore, participants also mentioned other challenging aspects for implementing PBL, including the lack of physical facilities, limited materials, and small classroom sizes. Teachers struggled as they tried to manage students' work and interactions within small classrooms and limited access to computers 
and the Internet. The majority of participants further struggled to provide their students with the required materials, as PBL projects required different resources according to the type of the project. One teacher commented:

"The project has to have its own budget because we can't ask the students to bring everything from their houses.... Sometimes the students tell me they don't have anything to bring." (T4, In2)

Finally implementing PBL within the given conditions raised an additional workload for teachers, which influenced their work motivation. As one teacher, "They should not put all the burden on teachers. It takes a miracle for a teacher to make all these happen on our own. We need support, materials and collaboration with others." (T5, In2).

\subsection{Coping strategies}

Being requested to implement PBL under the aforementioned conditions and challenges, teachers developed different strategies to cope with the situation. These coping strategies were most notably related to the school environment.

One particular coping strategy documented by teachers in school A and B was the satisficing strategy, or finding a temporary solution that is considered satisfactory in the given situation. In school A, participants did not receive any professional development before the implementation of the PBL sessions. In school B, participants were informed of the policy guidelines from their coordinator who attended the professional development workshop offered by the MOEHE. In both school cases, participants claimed having to work out the lesson plans without support. To overcome this challenge, teachers from both schools decided to complete the projects to the best of their understanding, without interfering or judging one another. Though teachers had found a temporary solution that helped them complete the work as required, many still wanted to "get over the PBL year" and go back to doing work as usual.

In school C, a different coping strategy was used as teacher collaboration was strongly encouraged by the school. According to participants, the principal at their school believed in the value of PBL if conducted in an appropriate way. Working within the safe premises of a community of practice, teachers expressed confidence in managing the implementation of PBL and transforming any challenge into an asset. Observation data further confirmed teachers' collaborative strategies, as they supported one another inside the classroom during the PBL sessions. Teachers further appreciated the autonomy in decisionmaking, where they could develop ideas without the fear of failure or negative judgement. As the English subject coordinator stated:

"Since we have to do it, why don't we find a way to benefit from this... and do it in a way that will benefit students" (T11, In 1)

Consequently, the collaborative culture helped teachers overcome their insecurity and lack of confidence, as one teacher explained: 
"In our school we like challenges and we take it as a positive challenge...Although I am a new teacher with only two years' experience, I am not afraid of this challenge; in my school, the challenges should be positive things and I believe I will learn a lot from this [implementing PBL]." (T8, In1)

Having a collaborative culture further allowed teachers to improve their PBL instructional practices in the second round of implementation, as one teacher stated:

"Before starting PBL this semester, we firstly discussed what's good and beneficial for our students. Then, we discussed what were the areas that we struggled in and how we can solve them. While designing the plan for PBL, we considered the outcomes of our discussion; the topic, students' level, the assessment tools, how we can help our students and what we can provide them with. And then we had a meeting to discuss the PBL topic of each grade, how they can apply it, and what are the expected outcomes of students... we also adjusted the expected outcome to fit each grade... and designed three assessment tools for us to know the outcome of PBL." (T11, In2)

With the introduction of PBL as another reform initiative at school $\mathrm{C}$, teachers developed their own version of community of practice, which they called CLP (cooperation, learning and planning). In their CLPs, teachers collaborated using brainstorming, peer learning, reflecting, co-teaching, and peer evaluation. As one teacher said:

"We learned a lot and know more about how to do PBL this semester. We have CLP now meaning cooperation, learning and preparation. We take regular preparation meetings and feel more prepared." (T9, In2)

\section{Discussion}

The study examined EFL primary teachers' first year experiences implementing PBL in Qatari government schools. Results of the study suggested that fidelity of implementation in the case of PBL is more complex than faithfully practicing PBL by following policy guidelines.

In general, outcomes of the study identified a gap in the definition of PBL offered in the mandated policy document when compared to the PBL principles summarized in the literature. Following the framework of fidelity of implementation (Dane \& Schneider, 1998), all the case schools in the current study had similar experiences with regards to adherence, dosage and program differentiation. Instead of being at the core of the curriculum, PBL was merely introduced as an add-on to the existing curriculum without further alignment with assessment methods (lack of adherence). In addition, as specified in the policy document, only a limited amount of time was allocated to the implementation of PBL (low dosage), and all three schools were involved in several other mandated initiatives (lack of program differentiation). According to research findings, these factors led to low morale among participants, and 
consequently low fidelity, in the initial stages of implementation. Working under such conditions while enduring an extra workload can be a demotivating factor when implementing educational innovation (Al Said, Du, ALKhatib, Romanowski \& Barham, 2019). In general, the adaptation at the policy level created constraints to faithful implementation among teachers and may have potentially limited the outcomes of the overall initiative.

During the process of implementation, teachers reported a dilemma between fidelity and adaptation (Hmelo-Silver, 2012; Ravitzs, 2010). Despite their attempt to follow the procedures as mandated by the MOEHE guidelines, they also tried to make sense of the initiative which they originally lacked sufficient understanding of, thus, leading to program adaptation in their different contexts. In this process of negotiation, they generated their own understanding of PBL and associated individual meanings for implementation, which has been documented in the literature as a process of teacher engagement and learning alongside their students (Fullan, 2014). In negotiating a balance between fidelity and adaptation, teachers become "activators" (Fullan, 2014), who modified the educational innovation to best fit their students' learning. It was not the aim of the current study to evaluate the extent to which this adaptation was appropriate or successful, therefore, further attention is needed to explore the level of teachers' adjustment versus fidelity in implementing PBL.

The study has thus contributed to the extent literature in the field of PBL by highlighting the implementation of PBL in the EFL primary classroom. First, the study confirmed previous studies conducted at the primary level in terms of improved student motivation and engagement (Dole, Bloom \& Doss, 2017; Drake \& Long, 2009; Jerzembek \& Murphy, 2013; Merritt, Lee, Rillero \& Kinach, 2017). The study also echoed previous studies in that implementing PBL at lower educational levels may demand more direct classroom intervention and different teacher roles (Dole, Bloom \& Doss, 2017; Drake \& Long, 2009; Al Said, $\mathrm{Du}$, ALKhatib, Romanowski \& Barham, 2019). Nevertheless, results of the current study identified further difficulties in implementing PBL in the EFL classroom, related to students' language proficiency and age level. Further research is needed to examine the most appropriate ways to implement PBL for young learners with limited language proficiency (Ruan, Duan \& Du, 2015).

Similar to the implementation of any innovative practice, several challenges were articulated by the participants in the current study. Common challenges included adjusting to changing roles (Ertmer \& Simons, 2006), selecting topics and balancing PBL with overall curricular demands (Du, Ebead, Sabah, Ma \& Naji, 2019; Nariman \& Chrispeels, 2016), and collaborating with other teachers (Fullan, 2014; Tamin \& Grant, 2013). Nevertheless, teachers in the current study did not identify those challenges related to student collaboration nor learning outcomes (Ertmer \& Simons, 2006; Tamin \& Grant, 2013; Al Said, Du, ALKhatib, Romanowski \& Barham, 2019). This may have been due to the fact that the implementation of PBL was relatively new, which furthers suggests that teachers experience challenges that are very much concerned with readiness and 
preparation for the innovation in the initial stages of implementation (Adelman \& Taylor, 2010; Ertmer \& Simons, 2006).

Outcomes of the study further identified the conditions, constraints and factors influencing teachers' decisions in balancing fidelity and adaptation. First, limited time allocation was reported as the major challenge during the initial implementation of PBL in the current study. Although there is little evidence on how long instructional reforms take to produce positive results, Borman, Hewes, Overman and Brown (2003) have suggested that stronger effects on student achievement can be expected in schools that implement reform initiatives for five years and above. Following this suggestion, the ongoing change initiative in Qatar should become a long-term plan involving a cyclic process of evaluation, revision, and implementation (Fullan, 2014). A positive aspect for the longevity and success of the initiative is the fact that it was mandated at the policy level (Hmelo-Silver, 2012; Wurdinger, 2016). Second, results of the study highlighted the need for a culture of change to become the norm, in which teachers continuously adapt and change their conceptions, beliefs, values, and most evidently their accustomed practices of instruction and assessment $(\mathrm{Du}, \mathrm{Su} \&$ Liu, 2013; Ravitzs, 2010). Particularly when change agents operate at the highest level of the hierarchy, a flexible school culture makes it easier for teachers and students to change their practices and implement innovations more successfully (Lam, Cheng \& Choy, 2010; Ravitzs, 2010).

To further the success of the innovation, teachers need to enjoy higher levels of teacher autonomy and collaboration, which remain to be problematic and hence demand further efforts from both individual teachers and school supports (Duan, Du \& Yu, 2018; Lam, Cheng \& Choy, 2010). Second, the study revealed that the majority of teachers went through the entire year of PBL implementation without the necessary levels of readiness for change (Fullan, 2014). They reported a lack of understanding of and skills for PBL implementation, which attributed to their confusion and lack of confidence in managing the initial stages of implementation. To prepare teachers for implementation, it is essential to provide needed physical facilities (Durlak \& DuPre, 2008), as well as sufficient teacher development activities that foster sharing and reflection on experiences (Fullan, 2014). Such support practices are bound to promote teacher motivation, beliefs, positive attitudes, and relevant skills (Bliss \& Wanless, 2018). Particularly when an innovation is imported from a socio-cultural context very different from the one it is implemented, further attention to the characteristics of both contexts becomes necessary $(\mathrm{Hu}, 2002)$.

\section{Conclusion}

In sum, the study provided insight into teachers' initial implementation of an educational innovation, such as PBL, in the EFL primary education setting. It also explored the conditions, constraints and contextual factors that influenced teachers' choices in balancing fidelity and adaptation. In brief, the study provided the following highlights:

- Adapting PBL at the policy level created constraints to faithful implementation. 
- Teachers negotiated the balance between fidelity and adaptation.

- Implementing PBL in the EFL classroom demands coping with a complexity of factors.

- Support, professional development, and a collaborative culture are recommended.

Results of the study are provisional due to a few limitations including the small number of participants, potential bias in the choice of schools, and limited opportunities for observations. Observational data is recommended for further research on fidelity because they are less susceptible to social desirability bias than data obtained from the reports of service providers or participants (Dane \& Schneider, 1998). Results of the study suggested that further PBL implementation at a systemic level should take careful consideration of teachers' understanding, knowledge, motivation, and skills for practicing PBL in their given contexts (Al Said, Du, ALKhatib, Romanowski \& Barham, 2019). Leader support, teacher autonomy and collaboration can help create a supportive environment that may maximize the implementation effects (Chaaban \& Du, 2017). Further research is also recommended to investigate teachers' fidelity versus adaptation on a larger scale and evaluate the results of those choices in relation to student learning outcome (O'Donnell, 2008; Ravitzs, 2010).

\section{References}

Adelman, H. S., \& Taylor, L. (2007). Systemic change for school improvement. Journal of Educational and Psychological Consultation, 17(1), 55-77.

Al Said, R. S., Du, X., ALKhatib, H. A. H., Romanowski, M. H., \& Barham, A. I. I. (2019). Math Teachers' Beliefs, Practices, and Belief Change in Implementing Problem Based Learning in Qatari Primary Governmental School. EURASIA Journal of Mathematics, Science and Technology Education, 15(5). https:// doi.org/10.29333/ejmste/105849

Bell, S. (2010). Project-based learning for the 21st century: Skills for the future. The Clearing House, 83(2), 39-43. https:/ / doi.org/10.1080/00098650903505415

Beckett, G. H. (2006). Project-based second and foreign language education. In Beckett, G., H. \& P. C. Miller (Eds.), Project-Based Second and Foreign Language education: Past, present, and future (pp. 1-15). Greenwich, Connecticut: Information Age Publishing.

Bliss, C. M., \& Wanless, S. B. (2018). Development and initial investigation of a selfreport measure of teachers' readiness to implement. Journal of Educational Change, 19(2), 269-291. https:// doi.org/10.1007/s10833-018-9324-5

Borman, G. D., Hewes, G. M., Overman, L. T., \& Brown, S. (2003). Comprehensive school reform and achievement: A meta-analysis. Review of educational research, 73(2), 125-230. https://doi.org/10.3102/00346543073002125

Chaaban, Y., \& Du, X. (2017). Novice teachers' job satisfaction and coping strategies: Overcoming contextual challenges at Qatari government schools. Teaching and Teacher Education, 67, 340-350. https:// doi.org/10.1016/j.tate.2017.07.002

Correnti, R., \& Rowan, B. (2007). Opening up the black box: Literacy instruction in schools participating in three comprehensive school reform programs. American Educational Research Journal, 44(2), 298-339. https://doi.org/10.3102/0002831207302501 
Creswell, J. W., \& Poth, C. N. (2018). Qualitative inquiry and research design: Choosing among five approaches (4th Ed.). Thousand Oaks, CA: Sage.

Dane, A. V., \& Schneider, B. H. (1998). Program integrity in primary and early secondary prevention: Are implementation effects out of control. Clinical Psychology Review, 18, 23-45. https://doi.org/10.1016/S0272-7358(97)00043-3

Dole, S., Bloom, L., \& Doss, K. K. (2017). Engaged learning: Impact of PBL and PjBL with elementary and middle grade students. Interdisciplinary Journal of Problem-Based Learning, 11(2), 1-9. https:/ / doi.org/10.7771/1541-5015.1685

Drake, K. N., \& Long, D. (2009). Rebecca's in the dark: A comparative study of problembased learning and direct instruction/experiential learning in two 4th-grade class- rooms. Journal of Elementary Science Education, 21(1), 1-16. https://www.jstor.org/stable/43155840

Du, X., Ebead, U., Sabah, S., Ma, J., \& Naji, K. K. (2019). Engineering Students' Approaches to Learning and Views on Collaboration: How do both Evolve in a PBL Environment and What are their Contributing and Constraining Factors? EURASIA Journal of Mathematics, Science and Technology Education, 15(11):em1774. https:// doi.org/10.29333/ejmste/106197

Du, X., Su, L., \& Liu, J. (2013). Developing sustainability curricula using the PBL method in a Chinese context. Journal of Cleaner Production, 61, 80-88. https:// doi.org/10.1016/j.jclepro.2013.01.012

Duan, X., Du, X., \& Yu, K. (2018). School Culture and School Effectiveness: The Mediating Effect of Teachers' Job Satisfaction. International Journal of Learning, Teaching and Educational Research, 17(5). https://doi.org/10.26803/ijlter.17.5.2

Durlak, J. A., \& DuPre, E. P. (2008). Implementation matters: A review of research on the influence of implementation on program outcomes and the factors affecting implementation. American Journal of Community Psychology, 41(3-4), 327-350. https:// doi.org/10.1007/s10464-008-9165-0

Ertmer, P. A., \& Simons, K. D. (2006). Jumping the PBL Implementation Hurdle: Supporting the Efforts of K-12 Teachers. Interdisciplinary Journal of Problem-Based Learning, 1(1). https:/ / doi.org/10.7771/1541-5015.1005

Fragoulis, I., \& Tsiplakides, I. (2009). Project-based learning in the teaching of English as a foreign language in Greek primary schools: From theory to practice. English Language Teaching, 2(3), 113-119.

Fullan, M. (2007). The meaning of educational change. New York: Teachers College Press.

Fullan, M. (2014). Teacher development and educational change. UK, London: RoutledgeFalmer.

Grant, M. M. (2011). Learning, beliefs, and products: Students' perspectives with projectbased learning. Interdisciplinary Journal of Problem-based Learning, 5(2), 37-69. https://doi.org/10.7771/1541-5015.1254

Helle, L., Tynjälä, P., \& Olkinuora, E. (2006). Project-based learning in post-secondary education-theory, practice and rubber sling shots. Higher Education, 51(2), 287314. https://10.1007/s10734-004-6386-5

Hmelo-Silver, C. E. (2012). International perspectives on problem-based learning: Contexts, cultures, challenges, and adaptations. Interdisciplinary Journal of Problem-Based Learning, 6(1), 3. https://doi.org/10.7771/1541-5015.1310

$\mathrm{Hu}, \mathrm{G}$. (2002). Potential cultural resistance to pedagogical imports: The case of communicative language teaching in china. Language Culture and Curriculum, 15(2), 93-105. https:// doi.org/10.1080/07908310208666636

Hung, W. (2011). Theory to reality: A few issues in implementing problem-based learning. 
Jerzembek, G., \& Murphy, S. (2013). A narrative review of problem-based learning with school-aged children: implementation and outcomes. Educational Review, 65(2), 206-218. https://doi.org/10.1080/00131911.2012.659655

Jumaat, N. F., Tasir, Z., Halim, N. D. A., \& Ashari, Z. M. (2017). Project-based learning from constructivism point of view. Advanced Science Letters, 23(8), 7404-7406. https://doi.org/10.1166/asl.2017.9605

Kaldi, S., Filippatou, D., \& Govaris, C. (2011). Project-based learning in primary schools: Effects on pupils' learning and attitudes. Education 3-13, 39(1), 35-47. https://doi.org/10.1080/03004270903179538

Krajcik, J. S., \& Czerniak, C. M. (2014). Teaching science in elementary and middle school: A project-based approach. UK, Oxford: Routledge.

Kvale, S., \& Brinkmann, S. (2009). Interviews: Learning the craft of qualitative research. Thousand Oaks: SAGE.

Lam, S.-F., Cheng, R. W.-Y., \& Choy, H. C. (2010). School support and teacher motivation to implement project-based learning. Learning and Instruction, 20(6), 487-497. https://doi.org/10.1016/j.learninstruc.2009.07.003

Lee, J. S., Blackwell, S., Drake, J., \& Moran, K. A. (2014). Taking a leap of faith: Redefining teaching and learning in higher education through project-based learning. Interdisciplinary Journal of Problem-Based Learning, 8(2), 2. https://doi.org/10.7771/1541-5015.1426

Merriam, S. B. (1998). Qualitative research and case study applications in education. San Francisco, CA: Jossey-Bass.

Merritt, J., Lee, M., Rillero, P., \& Kinach, B. M. (2017). Problem-Based Learning in K-8 Mathematics and Science Education: A Literature Review. Interdisciplinary Journal of Problem-Based Learning, 11(2). https:// doi.org/10.7771/1541-5015.1674

Mitchell, S., Foulger, T. S., Wetzel, K., \& Rathkey, C. (2009). The negotiated project approach: Project-based learning without leaving the standards behind. Early Childhood Education Journal, 36(4), 339-346.

Nariman, N., \& Chrispeels, J. (2016). PBL in the era of reform standards: Challenges and benefits perceived by teachers in one elementary school. Interdisciplinary Journal of Problem-Based Learning, 10(1), 5. https://doi.org/10.7771/1541-5015.1521

O'Donnell, C. L. (2008). Defining, conceptualizing, and measuring fidelity of implementation and its relationship to outcomes in K-12 curriculum intervention research. Review of Educational Research, 78(1), 33-84. https://doi.org/10.3102/0034654307313793

Prince, M. J., \& Felder, R. M. (2006). Inductive teaching and learning methods: Definitions, comparisons, and research bases. Journal of Engineering Education, 95(2), 123-138. https://doi.org/10.1002/j.2168-9830.2006.tb00884.x

Ravitz, J. (2010). Beyond changing culture in small high schools: Reform models and changing instruction with project-based learning. Peabody Journal of Education, 85(3), 290-312. https://doi.org/10.1080/0161956X.2010.491432

Ruan, Y., Duan, X., \& Du, X. Y. (2015). Tasks and learner motivation in learning Chinese as a foreign language. Language, culture and Curriculum, 28(2), 170-190. https:// doi.org/10.1080/07908318.2015.1032303

Saldaña, J. (2016). The coding manual for qualitative researchers (3rd ed.). Thousand Oaks, CA: Sage.

Savery, J. R. (2006). Overview of Problem-based Learning: Definition and Distinctions. Interdisciplinary Journal of Problem-Based Learning, 1(1), 9-20.

Stake, R. E. (1995). The art of case study research. Thousand Oaks, CA: SAGE Publications. 
Stoller, F. (2006). Establishing a theoretical foundation for project-based learning in second and foreign language contexts. In Beckett, G., H. \& P. C. Miller (Eds.), Project-Based Second and Foreign Language education: past, present, and future (pp. 19-40). Greenwich, Connecticut: Information Age Publishing.

Tamim, S. R., \& Grant, M. M. (2013). Definitions and Uses: Case Study of Teachers Implementing Project-based Learning. Interdisciplinary Journal of Problem-Based Learning, 7(2). https://doi.org/10.7771/1541-5015.1323

Thomas, W. (2000). A Review of Research on Project Based Learning. http://www.bobpearlman.org/BestPractices/ PBL_Research.pdf. Retrieved Dec $6^{\text {th }}, 2017$.

Troyer, M. (2017). Teacher implementation of an adolescent reading intervention. Teaching and Teacher Education, 65, 21-33. https:// doi.org/10.1016/j.tate.2017.03.005

Yin, R. K. (2014). Case study research: design and methods (5th ed.). Thousand Oaks, CA: Sage.

Wurdinger, S. D. (2016). The Power of Project-based Learning: Helping Students Develop Important Life Skills. Rowman \& Littlefield.

\section{Appendix 1 Interview guidelines}

First round 2017 Fall

1. Could you please talk about your own background - where are you originally from? Your educational background? How long you have been in Qatar and how long you have been working in your current job?

2. What is the background of introducing PBL to Qatar government schools? (For example: Why did the Ministry decide to include PBL into the curriculum? Or What do you think is the motive behind including PBL into the Qatari curriculum? What are the objectives and goals of this implementation? etc.)

3. How do you define PBL? Have you experienced PBL as a student?

4. How would you define good learning and good teaching?

5. In which ways do you think PBL leads to good teaching and learning?

6. What is the role of the teacher in a classroom where PBL is being implemented? How should the teacher's role be different before PBL? How do you see your own role in this classroom?

7. How to you think PBL is being implemented in your school and in the Qatari context?

8. What kind of knowledge, skills and competences are needed as a teacher to implement PBL?

9. What kind of PD activities have been provided to the teachers so far? How do these PD activities work in order to help teachers during the implementation of PBL?

10. What kind of PD activities are further needed in your opinion?

11. What challenges and issues have been experienced during the implementation so far?

Second round 2018 Spring

1. How have you been implementing PBL this semester? Please describe the projects and the way you planned and implemented them in the classroom. 
2. Were there any changes between the first semester and this semester in the way you implemented PBL? (for e.g, the kinds of projects completed, the collaboration with other teachers, the students' skills in working on the projects)

3. Has there been any improvements in the support you received for implementing PBL? (for example, from the coordinator, the principals, or the ministry supervisors?)

4. What were some of the problems you faced with the first PBL implementation? Are you still facing these same challenges?

5. What do you think are the benefits of PBL on students' learning? Do you think PBL makes a difference in the students' performance such as motivation, skills, and grades?

6. Do you think PBL has any drawbacks on these aspects?

7. Do you think PBL is appropriate for primary school students?

8. Do you think PBL is suitable for the English curriculum?

9. What kinds of support do you think is necessary for moving forward with implementing PBL next year? What should be done to improve the implementation next academic year?

10. What do you think will be the future of implementing PBL in Qatar governmental schools? 